\title{
In vitro effect of medicinal plants used to treat erectile dysfunction on smooth muscle relaxation and human sperm
}

\author{
N.C. Rakuambo, J.J.M. Meyer, A. Hussein, C. Huyser, S.P. Mdlalose and T.G. \\ Raidani
}

\begin{abstract}
Chloroform and ethanol extracts of root bark of Securidaca longepedunculata, Wrightia natalensis and Rhoicissus tridentata were investigated for their in vitro activity on the contraction of corpus cavernosal smooth muscle of white New Zealand rabbits. Some of the extracts of these plants relaxed the corpus cavernosal smooth muscle at low concentrations. The highest activity was obtained from Securidaca longepedunculata chloroform extracts at a concentration of $13.0 \mathrm{mg} / \mathrm{ml}$, which induced $66.6 \%$ relaxation. Viagra was used as a positive control in this study. Extracts of Securidaca longepedunculata added to human spermatozoa affected certain sperm parameters negatively at $6.5 \mathrm{mg} / \mathrm{ml}$ and higher whilst there was no effect at $1.0 \mathrm{mg} / \mathrm{ml}$.
\end{abstract}

\section{Article Outline}

1. Introduction

2. Materials and methods

2.1. Plant material

2.2. Plant extraction for smooth muscle relaxation experiment

2.3. Plant extraction for sperm parameter experiment

2.4. Preparation of corpus cavernosal smooth muscle

2.5. Smooth muscle relaxation bioassay

2.6. Sperm processing, motility, vitality and membrane integrity

2.7. Statistical analysis

3. Results

3.1. Smooth muscle relaxation

3.2. Effect of extracts on sperm parameters

4. Discussion

Acknowledgements

References 


\section{Introduction}

Despite of all the advances in modern and orthodox medicine, traditional medicine still plays a significant role in the lives of many people, particularly in Venda (a region in the Limpopo province of South Africa) (Mabogo, 1990).

Erectile dysfunction, known clinically as an inability to obtain or maintain an erection (Guirguis, 1998) is a medical problem affecting young as well as old men. A recent male aging study showed that $52 \%$ of respondents have some degree of erectile dysfunction, with 35\% of men aged 40-70 reporting moderate or complete impotence (Morgentaler, 1999). Although a number of treatments became available in the last two decades, problems with costs, efficacy, safety and ease to administer were experienced. These treatments ranged from herbal remedies used by native healers, mostly in the Eastern countries, to the more sophisticated designer drugs, which are based on a better understanding of the physiological mechanism of erection (Guirguis, 1998).

A number of herbal plants such as Securidaca longepedunculata (Fresen) (Polygalaceae), Wrightia natalensis (Stapf) (Apocynaceae) and Rhoicissus tridentata L.f. (Wild and R.B. Drumm) (Vitaceae) found in Venda are used to treat erectile dysfunction. Securidaca longepedunculata is used as a general remedy for several other ailments such as coughs, colds, fever, backache, toothache, sleeping sickness, venereal disease, malaria, inflammation, rheumatism, snakebite, tuberculosis, ulcers and pneumonia (Galeffi et al., 1990). However, there has been no scientific investigation on the in vitro activity of erectile dysfunction of these species.

Palgrave (1977) reported that Securidaca longepedunculata is also used as a contraceptive. Very few scientific studies have been conducted on herbal plants used in the treatment of infertility. Ondrizek et al., 1999 and Ondrizek et al., 1999 reported the effect of extracts of Hypericum perforatum, Serenoa repens, Sabal serrulatum and Ginkgo biloba on sperm cells. The results indicated that at a concentration of $0.6 \mathrm{mg} / \mathrm{ml}$ motility was inhibited within an hour of incubation by Hypericum perforatum and after $24 \mathrm{~h}$ of incubation by Serenoa repens $(9.0 \mathrm{mg} / \mathrm{ml})$ suggesting a spermicidal effect.

This study was conducted to investigate whether extracts of these three species have a direct relaxing effect on rabbit corpus cavernosum smooth muscle and also to analyse the effect of Securidaca longepedunculata extracts on human sperm cells.

\section{Materials and methods}

\subsection{Plant material}

The root bark of Securidaca longepedunculata, Wrightia natalensis and Rhoicissus tridentata were collected in Venda (South Africa) during June 1999. Voucher specimens (NCR. 16, 17 and 18, respectively) were deposited and identified at the H.G.W.J. Schweickerdt Herbarium (PRU), University of Pretoria. 


\subsection{Plant extraction for smooth muscle relaxation experiment}

Chloroform extracts of root bark of Securidaca longepedunculata (40.6 g), Wrightia natalensis $(55.6 \mathrm{~g})$ and Rhoicissus tridentata $(12.7 \mathrm{~g})$ were prepared by homogenizing the powdered root bark in chloroform (3.0 l) and stirring under reflux for $12 \mathrm{~h}$. The extracts were filtered and concentrated to dryness under reduced pressure at $37^{\circ} \mathrm{C}$. The resultant residue was later dissolved in $1.0 \%$ dimethylsulfoxide (DMSO) to concentrations of $100.0,50.0$ and $1.0 \mathrm{mg} / \mathrm{ml}$. Ethanol extracts of root bark of Securidaca longepedunculata (39.9 g), Wrightia natalensis (51.8 g) and Rhoicissus tridentata (12.6 g) were prepared as described for chloroform extracts.

\subsection{Plant extraction for sperm parameter experiment}

An ethanol extract of Securidaca longepedunculata was prepared by homogenizing $38.3 \mathrm{~g}$ of the powdered root bark in ethanol and extracting it for $24 \mathrm{~h}$. The extract was filtered and concentrated to dryness under reduced pressure at $37^{\circ} \mathrm{C}$. The resultant residue was dissolved in Ham's-F10 solution (Sigma) prepared with deionised, double sterilized endotoxin-free Baxter water (Sabax, Adcock Ingram). The solution was supplemented with $0.2452 \mathrm{~g}$ Ca-lactate (Sigma), $0.05 \mathrm{~g}$ penicillin-G (Sigma) and $2.1060 \mathrm{~g}$ sodium bicarbonate (Sigma). The media was filter sterilized (Sartorius, Minisart $0.2 \mu \mathrm{m}$ filter) and equilibrated to a $\mathrm{pH}$ of 7.3-7.4. An Osmomat 030 (Cryoscopic osmometer, Gynotec) was used to adjust the osmolarity of the media to $283.0 \pm 1 \mathrm{mOsm} / \mathrm{kg}$ (before use). Similarly, the media was adjusted to 293, 312.0, 377.0 and $440.0 \mathrm{mOsm} / \mathrm{kg}$ to compare these elevated osmolarities and extract concentrations on sperm motility.

\subsection{Preparation of corpus cavernosal smooth muscle}

The entire penis of New Zealand rabbits (mass 2.0-2.3 kg) was kept in Krebs-phosphate buffered saline aerated with $95.0 \% \mathrm{O}_{2}$ and $5.0 \% \mathrm{CO}_{2}$ for less than $30 \mathrm{~min}$. One or two strips of the corpus cavernosum smooth muscle (12 $\mathrm{mm}$ long and 1-2 mm thick) were dissected from each penis. The strips were mounted in an organ-bath chamber containing Krebs solution ( $\mathrm{pH} 7.3$ ) with the following composition: $\mathrm{NaCl}=7.01 \mathrm{~g} / 1, \mathrm{KCl}=0.34 \mathrm{~g} / \mathrm{l}$, $\mathrm{KH}_{2} \mathrm{PO}_{4}=0.1 \mathrm{~g} / 1, \mathrm{NaHCO}_{3}=1.99 \mathrm{~g} / 1, \mathrm{CaCl}_{2}=0.2 \mathrm{~g} / 1, \mathrm{MgSO}_{4}=0.3 \mathrm{~g} / \mathrm{l}$ and glucose $=1.8 \mathrm{~g} / 1$.

\subsection{Smooth muscle relaxation bioassay}

Strips of rabbit corpus cavernosum smooth muscle were mounted in a perfusion bath, with one end tied to the inside bottom of the perfusion bath and the other end to a thin wire connected to a Harvard isotonic force transducer for tension measurements (Drewes et al., 2002). Changes in isotonic tension were recorded on a chart polygraph by a recorder. The corpus cavernosum muscle was perfused with $2 \mathrm{ml} \mathrm{Krebs-PSS} \mathrm{buffered}$ saline and oxygenated with $95 \% \mathrm{O}_{2}$ and $5 \% \mathrm{CO}_{2}$ for 5 min to ascertain a stable baseline recording. This was followed by perfusion with $2 \mathrm{ml}$ of $\mathrm{CaCl}_{2}-\mathrm{PSS}(17.8 \mathrm{mg} / \mathrm{ml})$ to achieve muscle contraction. Baseline tension was set at the point of maximal contraction 
following the addition of calcium chloride into the experimental bath. The extracts to be analyzed were added after a stable contraction baseline had been obtained. The extracts (final concentrations 6.5 and $13.0 \mathrm{mg} / \mathrm{ml}$ ) were administered through superfusion of the corpus cavernosum smooth muscle in a temperature $\left(37^{\circ} \mathrm{C}\right)$ controlled perfusion bath. A frequency of $12 \mathrm{~Hz}$ was used during the experiment. The same procedure was repeated for the positive control, Viagra (Pfizer, $3.2 \times 10^{-5} \mathrm{mg} / \mathrm{ml}$ ).

\subsection{Sperm processing, motility, vitality and membrane integrity}

Fresh semen samples were obtained from a single donor to avoid inter-donor variability. Semen analyses were performed according to the protocol of the World Health Organization (WHO, 1999). The semen was washed three times after analysis and layered on top of a discontinuous two-layer colloid gradient of PureSperm ${ }^{\mathbb{B}}$ (Nidacon) in a $13.5 \mathrm{ml}$ centrifuge tube. The bottom layer consisted of $1.0 \mathrm{ml}$ of $80.0 \%$ PureSperm $^{\circledR}$ in Ham's F10, whilst the next layer contained $1.0 \mathrm{ml}$ of $40.0 \%$ PureSperm $^{\circledR}$ in Ham's F10 and $1.0 \mathrm{ml}$ of semen on top. The gradients were centrifuged at $300 \times g$ for $20 \mathrm{~min}$. The supernatant was removed from each tube and the pellet resuspended in $3.0 \mathrm{ml}$ sperm wash medium (Ham's F10 supplemented with human serum albumin serum-HAS [Vitrolife AB]). The tubes were then centrifuged at the same speed for $10 \mathrm{~min}$. The supernatant was removed and washed again with $3.0 \mathrm{ml} \mathrm{HSA}$ supplemented Ham's F10 at $300 \times g$ for $10 \mathrm{~min}$. The final sperm-pellet was resuspended in $1.0 \mathrm{ml} \mathrm{Ham}$ 's F10 (control) supplemented with HSA, or $1.0 \mathrm{ml}$ of medium supplemented with the herbal extract to final concentrations of $1.0,2.5,6.5$ and $10.0 \mathrm{mg} / \mathrm{ml}$. The sperm was then incubated at $37{ }^{\circ} \mathrm{C}$, under $6.0 \% \mathrm{CO}_{2}, 95 \%$ humidity in air with test tube tops loosened (for gaseous exchange) for $48 \mathrm{~h}$. Sperm motility analysis was performed after $0,4,24$, and $48 \mathrm{~h}$ of incubation. Motility was noted as rapid progressive motility or slow or sluggish progressive motility or non-progressive motility. The eosin-nigrosin and the Hypo Osmotic Swelling (HOS) tests (WHO manual, 1999) were performed after 24 and $48 \mathrm{~h}$ of incubation to determine sperm vitality and membrane integrity. All counts (motility, eosin-nigrosin and HOS) were performed in triplicate.

\subsection{Statistical analysis}

Three replicates were used in all experiments and the significance of differences among groups were determined using the Student's $t$-test, with differences considered significant at $P<0.01$ (Colabro et al., 1996 and Keaton and Clark, 1997).

\section{Results}

\subsection{Smooth muscle relaxation}

Securidaca longepedunculata, Wrightia natalensis and Rhoicissus tridentata extracts (chloroform and ethanol) stimulated dose-dependent relaxation (Table 1) in the corpus cavenosum smooth muscle at concentrations of 13.0 and $6.5 \mathrm{mg} / \mathrm{ml}$. The stimulation of relaxation was between 0 and $60 \mathrm{~s}$ after the application of the extracts. A Harvard isotonic transducer elicited relaxation of the strips of corpus cavenosum smooth muscle 
in a frequency-dependant manner and the relaxation was significantly more $(13.0 \mathrm{mg} / \mathrm{ml})$ when exposed to the Securidaca longepedunculata chloroform extract $(P<0.01 ; n=3)$ than the other two species. At an extract concentration of $13.0 \mathrm{mg} / \mathrm{ml}$ the relaxation induced was significantly higher $(P<0.01)$ than that of the $3.2 \times 10^{-5} \mathrm{mg} / \mathrm{ml}$ of Viagra (positive control), whilst the later induced relaxation was better than the plant extract at $6.5 \mathrm{mg} / \mathrm{ml}$. It was also found that the $1.0 \%$ of DMSO (negative control) used to dissolve the extracts, acted against the activity of the extracts by being responsible for $20.0 \%$ of contraction.

Table 1.

$\%$ Relaxation of pre-contracted rabbit corpus carvenosal smooth muscle in the presence of herbal extracts

\begin{tabular}{|l|l|l|l|l|}
\hline Plant species & \multicolumn{3}{|l|}{ Average \% relaxation $( \pm$ S.D.) } \\
\hline & \multicolumn{3}{|l|}{ Chloroform extracts } & \multicolumn{2}{l|}{ Ethanol extracts } \\
\hline & $\mathbf{1 3 . 0} \mathbf{~ m g} / \mathbf{m l}$ & $\mathbf{6 . 5} \mathbf{~ m g} / \mathbf{m l}$ & $\mathbf{1 3 . 0} \mathbf{~ m g} / \mathbf{m l}$ & $\mathbf{6 . 5} \mathbf{~ m g} / \mathbf{m l}$ \\
\hline Wrightia natalensis & $26.0 \pm 5.7$ & $18.0 \pm 0.9$ & $63.0 \pm 13.1^{\mathrm{a}}$ & $16.0 \pm 4.3$ \\
\hline Securidaca longepedunculata & $66.7 \pm 12.8^{\mathrm{a}}$ & $16.7 \pm 4.7$ & $55.0 \pm 7.1^{\mathrm{a}}$ & $17.6 \pm 6.1$ \\
\hline Rhoicissus tridentata & $30.7 \pm 3.3^{\mathrm{a}}$ & $1.7 \pm 2.4$ & $43.0 \pm 9.4^{\mathrm{a}}$ & $15.0 \pm 0.0$ \\
\hline
\end{tabular}

Viagra relaxed muscles $21.0 \%$ at $3.2 \times 10^{-5} \mathrm{mg} / \mathrm{ml}$ and DMSO contracted of the muscles $20.0 \%$ at a $1.0 \%$ concentration.

${ }^{a}$ Significant difference when compared to Viagra at $P<0.01$.

\subsection{Effect of extracts on sperm parameters}

The influence of 1.0, 2.5, 5.5 and $10 \mathrm{mg} / \mathrm{ml}$ extract of Securidaca longepedunculata on sperm motility is illustrated in Table 2 . The extracts did not affect the sperm's progressive motility at the concentration of $1.0 \mathrm{mg} / \mathrm{ml}$. However, progressive motility noticeably decreased after $4 \mathrm{~h}$ at $2.5 \mathrm{mg} / \mathrm{ml}$ and directly after addition $(0 \mathrm{~h})$ of the extracts at 6.5 and $10.0 \mathrm{mg} / \mathrm{ml}$. Sperm was immotile (non-progressive) and/or moving in random directions. Motility was severely affected after $24 \mathrm{~h}$ incubation at $2.5 \mathrm{mg} / \mathrm{ml}$ and after $4 \mathrm{~h}$ incubation at both 6.5 and $10 \mathrm{mg} / \mathrm{ml}(P<0.05)$. 
Table 2 .

Influence of Securidaca longepedunculata extracts (\% of control) on the progressive motility of human spermatozoa $( \pm$ S.D.)

\begin{tabular}{|l|l|l|l|l|}
\hline Concentration of extract $\mathbf{( m g} / \mathbf{m l})$ & \multicolumn{4}{l}{ Incubation period } \\
\hline & $\mathbf{0 ~ h}$ & $\mathbf{4} \mathbf{h}$ & $\mathbf{2 4} \mathbf{h}$ & $\mathbf{4 8 ~ h}$ \\
\hline 1.0 & $87.7 \pm 2.0$ & $80.9 \pm 3.0$ & $73.9 \pm 3.6$ & $64.0 \pm 5.4$ \\
\hline 2.5 & $82.2 \pm 6.6$ & $64.6 \pm 4.0$ & $40.0 \pm 2.9^{\mathrm{a}}$ & $5.1 \pm 1.0^{\mathrm{a}}$ \\
\hline 6.5 & $60.1 \pm 7.0$ & $1.8 \pm 1.8^{\mathrm{a}}$ & $0.0 \pm 0^{\mathrm{a}}$ & $0.0 \pm 0^{\mathrm{a}}$ \\
\hline 10.0 & $47.0 \pm 3.5^{\mathrm{a}}$ & $0.0 \pm 0^{\mathrm{a}}$ & $0.0 \pm 0^{\mathrm{a}}$ & $0.0 \pm 0^{\mathrm{a}}$ \\
\hline Control & $90.8 \pm 3.1$ & $86.4 \pm 2.0$ & $77.9 \pm 3.0$ & $70.0 \pm 4.0$ \\
\hline
\end{tabular}

${ }^{a}$ Significant difference when compared to control samples at $P<0.05$.

A similar pattern was noted when sperm vitality was tested using eosin-nigrosin after 24 and $48 \mathrm{~h}$ of incubation (Table 3 ). The supravital stain indicates the physical intactness of the sperm membrane and will only stain the sperm if it's membranes are not intact. The percentage viable spermatozoa should be the same or greater than the percentage motile spermatozoa. Approximately 50\% of spermatozoa showed outer sperm membrane damage after 24 and $48 \mathrm{~h}$ of incubation while only $36.0 \%$ of spermatozoa stained negatively (intact membranes) at $1.0 \mathrm{mg} / \mathrm{ml}$. When the extract's concentration was increased to $2.5,6.5$ and $10 \mathrm{mg} / \mathrm{ml}$, nearly all of the spermatozoa were non-viable. 
Table 3.

Sperm vitality (\%) assessment using eosin-nigrosin after 24 and $48 \mathrm{~h}$ of exposure to different concentrations of Securidaca longepedunculata extracts

\begin{tabular}{|l|l|l|}
\hline Concentration of extract $(\mathbf{m g} / \mathbf{m l})$ & \multicolumn{2}{|l|}{ Vitality (\%) of sperm \pm S.D. } \\
\hline & $\mathbf{2 4} \mathbf{h}$ & $\mathbf{4 8 ~ h}$ \\
\hline 1.0 & $37.2 \pm 1.6$ & $36.8 \pm 1.3$ \\
\hline 2.5 & $4.9 \pm 0.2^{\mathrm{a}}$ & $2.3 \pm 0.6^{\mathrm{a}}$ \\
\hline 6.5 & $0.0 \pm 0.0^{\mathrm{a}}$ & $0.0 \pm 0.0^{\mathrm{a}}$ \\
\hline 10.0 & $0.0 \pm 0.0^{\mathrm{a}}$ & $0.0 \pm 0.0^{\mathrm{a}}$ \\
\hline Control & $51.1 \pm 5.0$ & $50.0 \pm 3.9$ \\
\hline
\end{tabular}

${ }^{a}$ Significant difference when compared to control samples at $P<0.05$.

The HOS test, which indicates the sperm membrane's functional integrity through the membrane's reactive response to a hypo-osmotic milieu, also showed a progressive negative response with increased herbal extracts (Table 4). Addition of $1.0 \mathrm{mg} / \mathrm{ml} \mathrm{herbal}$ extract had no effect on sperm membrane integrity $(P<0.05)$.

Table 4.

Sperm membrane integrity (\%) assessment using the HOS test after 24 and $48 \mathrm{~h}$ of exposure to different concentrations of Securidaca longepedunculata extracts

\begin{tabular}{|l|l|l|}
\hline Concentration of extract $\mathbf{( m g / m l})$ & \multicolumn{2}{|l|}{ \% Membrane integrity } \\
\hline & $\mathbf{2 4} \mathbf{~ h}$ & $\mathbf{4 8} \mathbf{~ h}$ \\
\hline 1.0 & $72.2 \pm 2.3$ & $57.6 \pm 0.7$ \\
\hline 2.5 & $31.7 \pm 2.1^{\mathrm{a}}$ & $14.1 \pm 1.4^{\mathrm{a}}$ \\
\hline 6.5 & $13.6 \pm 2.0^{\mathrm{a}}$ & $12.5 \pm 1.5^{\mathrm{a}}$ \\
\hline 10.0 & $11.0 \pm 1.2^{\mathrm{a}}$ & $9.9 \pm 0.2^{\mathrm{a}}$ \\
\hline Control & $72.7 \pm 1.2$ & $68.7 \pm 1.7$ \\
\hline
\end{tabular}


Standard deviations are given in brackets.

${ }^{a}$ Significant difference when compared to control samples at $P<0.05$.

The osmolarity of the media supplemented with the plant extracts were $290 \mathrm{mOsmol} / \mathrm{kg}$ $(1.0 \mathrm{mg} / \mathrm{ml}$ of extract); $321 \mathrm{mOsmol} / \mathrm{kg}(6.5 \mathrm{mg} / \mathrm{ml})$ and $350 \mathrm{mOsmol} / \mathrm{kg}(13.0 \mathrm{mg} / \mathrm{ml})$, with a $\mathrm{pH}$ of $6.5 \pm 0.4$. The media supplemented with the plant extracts were similarly incubated at $37{ }^{\circ} \mathrm{C}$, under $6.0 \% \mathrm{CO}_{2}, 95 \%$ humidity in air, prior to use. Sperm motility in media with osmolarities ranging from 293 to $440 \mathrm{mOsmol} / \mathrm{kg}$ was compared to that of sperm processed in the standard control media $(283 \mathrm{mOsmol} / \mathrm{kg})$. No significant difference $(P>0.05)$ was noted between the progressive motility of the spermatozoa in relation to media osmolarity over time (Table 5).

Table 5.

Influence of osmolarity on the progressive motility ( $\% \pm$ S.D.) of spermatozoa over $48 \mathrm{~h}$

\begin{tabular}{|l|l|l|l|l|}
\hline Osmolarity of media (mOsmol/kg) & \multicolumn{4}{l}{ Incubation period } \\
\hline & $\mathbf{0 ~ h}$ & $\mathbf{4} \mathbf{h}$ & $\mathbf{2 4} \mathbf{h}$ & $\mathbf{4 8} \mathbf{~ h}$ \\
\hline 293.0 & $75.7 \pm 2.6$ & $74.1 \pm 3.2$ & $60.7 \pm 3.5$ & $35.3 \pm 3.4$ \\
\hline 312.0 & $75.7 \pm 5.0$ & $73.0 \pm 3.6$ & $61.6 \pm 5.0$ & $36.7 \pm 4.5$ \\
\hline 377.0 & $75.5 \pm 3.5$ & $74.2 \pm 3.2$ & $57.2 \pm 3.8$ & $30.5 \pm 4.3$ \\
\hline 440.0 & $72.5 \pm 4.5$ & $71.2 \pm 3.1$ & $53.2 \pm 4.1$ & $32.6 \pm 6.1$ \\
\hline Control (283.0) & $77.6 \pm 3.1$ & $76.1 \pm 3.7$ & $64.2 \pm 5.0$ & $39.9 \pm 3.2$ \\
\hline
\end{tabular}

\section{Discussion}

"The erect penis has always been a symbol of power, virility and fertility" (Guirguis, 1998). Inability to obtain or sustain an erection of the penis sufficient to permit satisfactory intercourse is clinically known as erectile dysfunction (Singer, 1994, Guirguis, 1998, Manecke and Mulhall, 1999 and Jequier, 2000) or sometimes referred to as primary or secondary impotence (Singer, 1994). Erectile dysfunction is known to be a major health problem and can cause considerable distress, unhappiness and relationship problems (Guirguis, 1998 and Morgentaler, 1999). The treatment of erectile dysfunction, however, can be many faceted and may involve more than one regimen (Jequier, 2000). In response to modern, sophisticated, chemical medication, there has been a renewed interest in medicinal plants in the treatment of sexual dysfunction, which are being shown to be both effective and safe (Adimoelja, 2000). Several medicinal plants have always 
been available and used to treat many ailments including impotence. Very few scientific studies have been conducted on herbal plants, which are used in the treatment of infertility and impotence, compared to that of sexually transmitted diseases. Ginseng has been used in the treatment of erectile dysfunction for thousands of years in China and is now used in many Western countries. Other herbal remedies for treating erectile dysfunction include: crushed seeds of fennel, licorice, pollen, sarsaparilla, asafetida, hops and Spanish fly (Guirguis, 1998). In a study by Kim et al. (1998) relaxation of the smooth muscle, which is associated with erection, was observed after the application of $0.5-$ $8.0 \mathrm{mg} / \mathrm{ml}$ of Panax ginseng extracts on rabbit corpus cavernosum smooth muscle. Similar results were obtained in the present study. It is therefore postulated that these extracts can facilitate the flow of blood into the penis. Erection cannot take place if the corpus carvenosum smooth muscle is contracted. The contraction of the corpus carvenosum smooth muscle is mediated by both translocations of calcium from extracellular sources and the release from intracellular sites especially the sarcoplasmic reticulum (Levin et al., 1997). Although there is a strong relationship between relaxation of the corpus carvenosum smooth muscle and sexual function (Keaton and Clark, 1997), it is also well known that there are many other factors that contribute to the deterioration of sexual function (Colabro et al., 1996).

The in vitro bioassays of this study indicated that Securidaca longepedunculata (Polygalaeae), Wrightia natalensis (Apocynaceae) and Rhoicissus tridentata (Vitaceae) are promising "future candidates" for the treatment of erectile dysfunction. These plants are used traditionally by the Vhavenda to care for many ailments including the treatment of erectile dysfunction. Root bark powder and portions are usually mixed with Mabundu (a traditional drink from water and different grains) and water, respectively, and the mixture is consumed immediately or within two days. Though, all these herbal extracts showed in vitro activity when tested on rabbit smooth muscle, Securidaca longepedunculata was the most active. This extract relaxed the smooth muscle effectively at a concentration of $13 \mathrm{mg} / \mathrm{ml}$ which seems high when compared to Viagra. However, when the activity of a purified compound from this species, 1,7-dimethoxy-2hydroxyxanthone, was tested in a previous study, it relaxed the smooth muscle at the low concentration of $1.8 \times 10^{-5} \mathrm{mg} / \mathrm{ml}$ (Rakuambo et al., 2004).

Herbal extracts from the root bark of Securidaca longepedunculata was further tested on human sperm parameters. Fertilization is primarily dependent on sperm motility and membrane integrity (Zheng and Zheng, 1996). The present study demonstrated an inhibitory effect of semi-purified herbal extracts $(>1.0 \mathrm{mg} / \mathrm{ml})$ from the root bark of Securidaca longepedunculata on sperm motility, vitality and membrane integrity. The results on sperm motility are comparable to the study conducted by Ondrizek et al. (1999) where Hypericum perforatum extracts $(0.6 \mathrm{mg} / \mathrm{ml})$ inhibited the sperm motility. Although the mechanism involved in the inhibition of sperm motility is unknown, it is clear that with no or poor sperm motility, vitality and membrane integrity, fertilization will be impaired. Results indicated that the inhibitory effect was caused by compounds in the extracts rather than the $\mathrm{pH}$ or the osmolarity of the media supplemented with herbal extracts. The results obtained here were in vitro and suggests that the low concentration might not affect the sperm in vivo. It is also possible that the compound or compounds in 
the plant extracts, responsible for relaxing rabbit corpus cavernosal smooth muscle tissue, might not affect the sperm cell as the extracts contain many different compounds. The possible association between contraceptive properties of Securidaca longepedunculata (Palgrave, 1977) and effects on sperm parameters, observed during the present study, warrants opportunities for future investigation. These preliminary results can be seen as the groundwork for further studies on isolation and identification of compounds and their mechanism of action. According to Drewes et al. (2002) the search is still on for a natural product that can deal successfully with erectile dysfunction. The present study highlighted the potential of South Africa's extraordinary plant-life and profound knowledge of traditional medicine, which can possibly be harvested for the treatment of sexual impotency.

\section{References}

Adimoelja, 2000 A. Adimoelja, Phytochemicals and the breakthrough of traditional herbs in the management of sexual dysfunction, International Journal of Andrology 23 (2000), pp. $82-84$.

Colabro et al., 1996 A. Colabro, G. Italiano, E.S. Pescatori, A. Marin, O. Gaetano, G. Abatangelo, G. Abatangelo and F. Pagano, Physiological aging and penile erectile function: a study in the rat, European Urology 29 (1996), pp. 240-244.

Drewes et al., 2002 S.E. Drewes, M.M. Horn, O.Q. Munro, J.T.B. Dhlamini, J.J.M. Meyer and N.C. Rakuambo, Pyrano-isoflavones with erectile-dysfunction activity from Eriosema kraussianum, Phytochemistry 59 (2002), pp. 739-747.

Galeffi et al., 1990 G. Galeffi, E. Federici, J.D. Msonthi, G.B. Marini-Bettolo and M. Nicoletti, New xanthones from Ectiadiopsis oblongifolia and Securidaca longipendunculata, Fitoterapia LXI (1990), pp. 79-81.

Guirguis, 1998 W.R. Guirguis, Oral treatment of erectile dysfunction: from herbal remedies to designer drugs, Journal of Sex and Marital Therapy 24 (1998), pp. 69-73.

Jequier, 2000 A.M. Jequier, Male Infertility: A Guide for the Clinician, Blackwell Science Ltd. (2000) pp. 200-225.

Keaton and Clark, 1997 A.K. Keaton and J.T. Clark, Effects of angiotensin 11 on sexual function, blood pressure, and fluid intake are differentially affected by AT-1 receptor blockade, Physiology and Behavior 64 (1997), pp. 339-346. 
Kim et al., 1998 H.J. Kim, D.S. Woo, G. Lee and J.J. Kim, The relaxation effects of ginseng saponin in rabbit corporal smooth muscle: is it a nitric oxide donor?, British Journal of Urology 82 (1998), pp. 744-748.

Levin et al., 1997 R.M. Levin, J.A. Hypolite, G. Broderik and A. Broderik, Evidence for a role of intracellular-calcium release in nitric oxide-stimulated relaxation of the rabbit corpus cavenorsum, Journal of Andrology 3 (1997), pp. 246-249.

Mabogo, 1990 Mabogo, D.E.N., 1990. The ethnobotany of Vhavenda. M.Sc. thesis, University of Pretoria, Pretoria.

Manecke and Mulhall, 1999 R.G. Manecke and J.P. Mulhall, Medical treatment of erectile dysfunction, Annals of Medicine 31 (1999), pp. 388-398.

Morgentaler, 1999 A. Morgentaler, Male impotence, Lancet 354 (1999), pp. 1713-1718.

Ondrizek et al., 1999 R.R. Ondrizek, P.J. Chan, W.C. Patton and A. King, Inhibition of human sperm motility by specific herbs used in alternative medicine, Journal of Assisted Reproduction and Genetics 16 (1999), pp. 87-91.

Palgrave, 1977 K.C. Palgrave, Trees of Southern Africa, Struik Publishers (Pty) Ltd., Cape Town (1977) pp. 388-389.

Rakuambo et al., 2004 N.C. Rakuambo, J.J.M. Meyer and A. Hussein, Xanthone isolated from Securidaca longepenunculata with activity against erectile dysfunction, Fitoterapia 75 (2004), pp. 497-499.

Singer, 1994 C. Singer, Erectile and ejaculatory disturbances: overview of diagnosis and treatment. In: C. Singerand and W.J. Weiner, Editors, Sexual Dysfunction, Futura publishing Company Inc., New York (1994), pp. 45-59.

WHO, 1999 World Health Organization, 1999. WHO laboratory manual for the examination of human semen and sperm-cervical mucus interaction, Cambridge University Press, pp. 6-29.

Zheng and Zheng, 1996 R-L. Zheng and H. Zheng, Effects of ferulic acid on fertile and asthenozoospermic infertile human sperm motility, viability, lipid peroxidation, and cyclic nucleotides, Free Radical Biology \& Medicine 22 (1996), pp. 581-586. 